\title{
Research of Hand-Drawn Illustrations and Its Application
}

\author{
Li Suo ${ }^{1}$, Yingwei $\mathbf{L i}^{1}$ \\ ${ }^{1}$ Jingdezhen Ceramic Institute, Jingdezhen, Jiangxi, 333403
}

Keywords: hand-drawn illustrations; application; social effect

\begin{abstract}
Hand-drawn illustration is a special kind of image art. Its own aesthetic features and forms of expression are an important part of Chinese traditional art, which has profoundly influenced the development of modern art design in many aspects such as cultural forms and aesthetic concepts. Hand-drawn illustrations are closely related to modern life, and are rich in a variety of painting techniques. Hand-drawn illustrations have been widely used in various fields of modern design today and have become an important shining point in the development of contemporary visual arts. As an important part of modern art design, packaging design must have a certain cultural foundation. Modern packaging design has chosen hand-drawn illustrations as an important means to enhance the charm of merchandise art.
\end{abstract}

\section{Introduction}

Illustration is an art form. It is an important form of visual communication in modern design. With its intuitive image, real sense of life, and appealing power, it occupies a special position in modern design and has been widely used in modern design. The various fields involved include cultural activities, social public utilities, commercial activities, and film and television culture. Whether it's random graffiti or thoughtful thinking, it's an illustration. It was originally used to increase the interest of the text in the publication, making the text part more vivid and more active in the hearts of readers. In today's various publications, the importance of illustrations has long gone far beyond text. Illustrators can not only emphasize the theme of ideas, but also enhance the appeal of art, contain profound connotations, and tell stories like the truth. emotion. The earliest illustrations in China appeared in the form of prints, which were the introduction of Buddhist culture and illustrated the scriptures in disguised form for propaganda. At present, historical records that China's earliest prints were published in the Tang Dynasty when the "Doroni scriptures." The exact date of the publication is the title page in the "Vajra Prajna" of the ninth year of Tang Xianzong (868). In the Song, Jin, and Yuan Dynasties, the book illustrations made great progress. The scope of application expanded to medical books, historical geography books, archeological illustrations, daily encyclopedias and other books, and color overlay illustrations appeared. During the Ming and Qing Dynasties, it can be said that the ancient art of illustration was in a period of great development. There were book-cutting industries all over the country, and different regions formed different styles. The illustrations are generally in the following forms: drawings at the beginning of the volume, illustrations in the text, pictures below or below, inside covers, front page paintings, and branding [1]. The hand-painted illustration is a true depiction of the heart of the illustrator, which is the manifestation of the individuality, the humanity's communication, and the embodiment of more true feelings integrated into the design. Hand-drawn illustrations make it easier for audiences to generate emotions, resonate, and better communicate design with the public. The hand-painted illustration is pregnant with rich sensibility and imaginative colors, depicts free and flexible lines, and has a unique traditional charm. Today, with the increasing influence of computer, hand-painted illustrations make the visual information more humane by virtue of its originality and artistic advantages.

\section{Styles and Techniques of Modern Hand-drawn Illustrations in Packaging Design}

First, realistic style. According to the specific themes and ideas, the illustrator designer can find 
the entry point such as image, color, and space relationship and carry out art recreation. This kind of processing can not only enhance the interestingness of the picture, but also make the modeling more individualistic characteristics of the illustrator. Second, abstract style. The abstract expression technique is an illustration form that abandons the visual natural phenomenon, and emphasizes the impersonal appearance of the image. Third, the decorative style. Decorative illustration design content is extremely wide, there are several categories of plant decorative patterns, animal decorative patterns, landscape decorative patterns, character decorative patterns and comprehensive decorative patterns. With rich imagination and strong language, the author uses the rules of exaggeration, change, repetition, comparison, induction, simplification, interlude, fiction, and symbolism to create [2].

\section{Principles and Emotional Expressions of Modern Hand-drawn Illustrations in Packaging Design}

First, it is pertinent: in commodity economy, any commodity is divided into fine categories. Businesses do this by simply subdividing consumer groups and their needs, and then offering products to different groups. Whether it is the product itself or the packaging of the product, it should be highly targeted, and the illustrations on the packaging must be subordinate to the products it serves. Second, reflect the nationality of packaging: With the intensification of the process of commodity circulation and global economic integration, commodities are becoming increasingly homogeneous. Want to stand out in similar products, not only rely on the quality of the product itself or brand influence, but also should seek breakthroughs in the design, the establishment of individual differences. To highlight its own quality and advantages in the white-hot competition, national design is undoubtedly a wise choice to choose. Nationalized packaging design is a concentrated manifestation of a nation's cultural tradition, aesthetic psychology, and aesthetic habits, and is a collection of national aesthetic consciousness and national design manifestations. The expression of cultural concepts and ethnic styles in packaging design will enrich the brand's connotation and make products have a certain cultural roots. Mr. Lu Xun once said: "Only nationalities are the world's." The more ethnic features are designed, the more they have world attributes, and the less likely they are to be assimilated by foreign cultural packaging design. Japan's packaging design gives people a near-perfect interpretation of the combination of traditional ethnic culture and modern design. Third, the packaging design culture that highlights the sense of the times is a process of historical development. It is based on the material society of this era and always bears the mark of the times. With the development and progress of social productivity, the packaging process and packaging materials are constantly updated. The best way to reflect the era of packaging is to keep pace with the times in the concept of packaging design. Packaging design can not only guide the aesthetic trend of social consumption, but also affected and restricted by popular life and culture. With the advent of the digital age, illustrations on modern packaging have undergone tremendous changes in creative methods, forms of expression, and applications. For example, digital illustration is a product of the computer age. Its premise is the application and popularization of computer and computer graphics software. With the advantages of its own powerful imitation capabilities and high-efficiency mapping, it will quickly be because of the low efficiency of painting and the narrow range of applications. The neglected illustration, a traditional art category, brings back to the world of packaging design. With the participation of digital illustrations, modern packaging presents a digital era [3].

First, to enhance the appeal of works: The hand-painted illustrations are original and unique, and they are the natural expression of design ideas. Whether it is a finely-written manuscript or an arbitrarily exaggerated manuscript, it is an emotional expression. Hand-painted illustrations reflect the designer's design inspiration in the works. They are full of life, simple, natural and close to life, making the works have a certain affinity. Second, to stimulate consumer interest: The uniqueness of hand-painted illustrations is that they can be realistically or abstractly represented in the designer's thinking, and maintain the designer's unique painting language. It is an extension of the designer's ideas, artistic concepts, and personality style. Third, to strengthen the persuasiveness of the works: 
With the ever-increasing standard of living, people's demands for aesthetics are also rising. Fast-paced life makes people's requirements for design higher. The features of the hand-drawn illustration design are prominent and prominent. It is the designer's display of life or perfection or realism, giving people a warm and comfortable sensation, allowing people to discover more beauty in their lives, and for this colorful variety. The society adds a touch of green. The hand-painted illustration in the modern design gives a pleasant feeling, and the illustration often represents the story. André Malraux said: "When a person has nothing to say, he absolutely cannot create works that communicate with the viewer."

\section{Prospect of Hand-drawn Illustrations in Packaging Design Applications}

As the most representative illustration design in the field of modern design, it has an inseparable relationship with the art of painting since its origin. Many expression techniques in hand-painted illustration art draw on and fuse the expression techniques of painting art. The combination of illustration art and packaging design makes the hand-painted illustrations both in the exploration of the diversity of performance techniques and in the spiritual connotation and theme conception of the packaging design. Both are conducive to the long-term development of the two and highlight the unique art. Charisma, which gives expression. Hand-painted illustration is a kind of special artistic expression that is full of personality and simple humanistic emotions. Its rich expression of emotions and skills makes hand-painted illustrations have more extensive application space and value. The application of illustration art in the design of commodity packaging can not only ensure the quality of the product itself, but also increase the commercial added value of the product, so that the illustration and the product on the packaging can be more in line with each other, so that it has the profound cultural qualities of hand-painted illustrations [5]. Lack of rustic life atmosphere. People's demand for aesthetics is constantly evolving with the development of the times. Designers need to constantly pay attention to the trend of world art and culture, pay attention to the changes of fashion elements and consumer psychology in all aspects. Only in this way can the illustration art be reflected in the design of commodity packaging. unique charm. As the saying goes, "people rely on clothes and horses rely on saddles," this phrase is used to describe the packaging design of products is not in violation of the law, and product packaging design is a special way of expression in contemporary consumer culture. It is not just a modern business culture. Material carriers, but also an important means of marketing. The use of hand-painted illustrations fully expresses the author's personal thoughts, emotions, cultures, styles, and qualities. It not only reflects the subject's subjective interpretation of color, but also has strong artistic expression and full artistic charm. The illustration packaging design on the market today has broken through the traditional model. The diversified style is more exquisite and uses a richer decoration technique to better bring out the characteristics of the company's products. It not only promotes the market's consumption, but also caters to people's needs. Visual needs. The visual effect of excellent packaging design should be far-sighted. Look at whether the packaging is obvious, eye-catching, and whether the color is harmonious. If you look closely, if you want to see whether the printing quality is correct and whether the color of the finished product is correct, there are many links that need to be considered. Therefore, excellent The packaging design should be both practical and innovative.

\section{Conclusion}

Illustrations are a manifestation of the Chinese nation's cultural and spiritual connotations. In today's general trend of economic integration of goods, China's packaging should keep a clear head. When packaging designers apply illustration elements to modern design, they should use this as the standard to examine the design, make up for the deficiencies in the design, enhance the overall sense of packaging design and quality, and enable the interaction between art and packaging design and the mutual improvement of the packaging design. To maximize the value of goods. Modern design needs its own style. This style needs a way of expression. Hand-painted illustrations play this role. It is an important part of modern design. It shows the inspiration and creativity of the 
person. It is designed with exquisite or rough or simple lines, freed from a simple computer meter, and makes modern design closer to life. It uses a flexible expression method and integrates the designer's design concept. It depicts a design work combining rationality and sensibility. The design of hand-drawn illustrations is as indispensable as human language, and modern design is bound to reach a new height of design with the participation of hand-drawn illustrations.

\section{References}

[1] Ji Can. Application of illustration art in modern brand packaging [J]. China Packaging Industry, 2016: 119.

[2] Zhou Ruguo. Application of Illustrator in Packaging Design [J]. Packaging Engineering, 2016:191-194.

[3] Sui He, Qian Jingjing. Application of Illustrator in Modern Packaging Design [J]. Packaging Engineering, 2014: 87-90.

[4] Dai Xuemei. Application Research of Hand-drawn Illustrations in Modern Design [J]. Packing World, 2017: 113-115.

[5] Yu Chenliang. Application of illustration in modern product packaging design [D]. East China Normal University, 2010. 